\title{
Applying Cognitive Linguistics to teaching English prepositions in the EFL classroom
}

\author{
David Wijaya $^{1^{*}}$ and Gabriella Ong $^{2}$ \\ The English Education Department, Faculty of Education and Language Universitas Katolik Indonesia Atma Jaya, \\ Jakarta, Indonesia ${ }^{1,2}$ \\ SMA Santa Ursula BSD, Kota Tangerang Selatan, Banten, Indonesia ${ }^{2}$
}

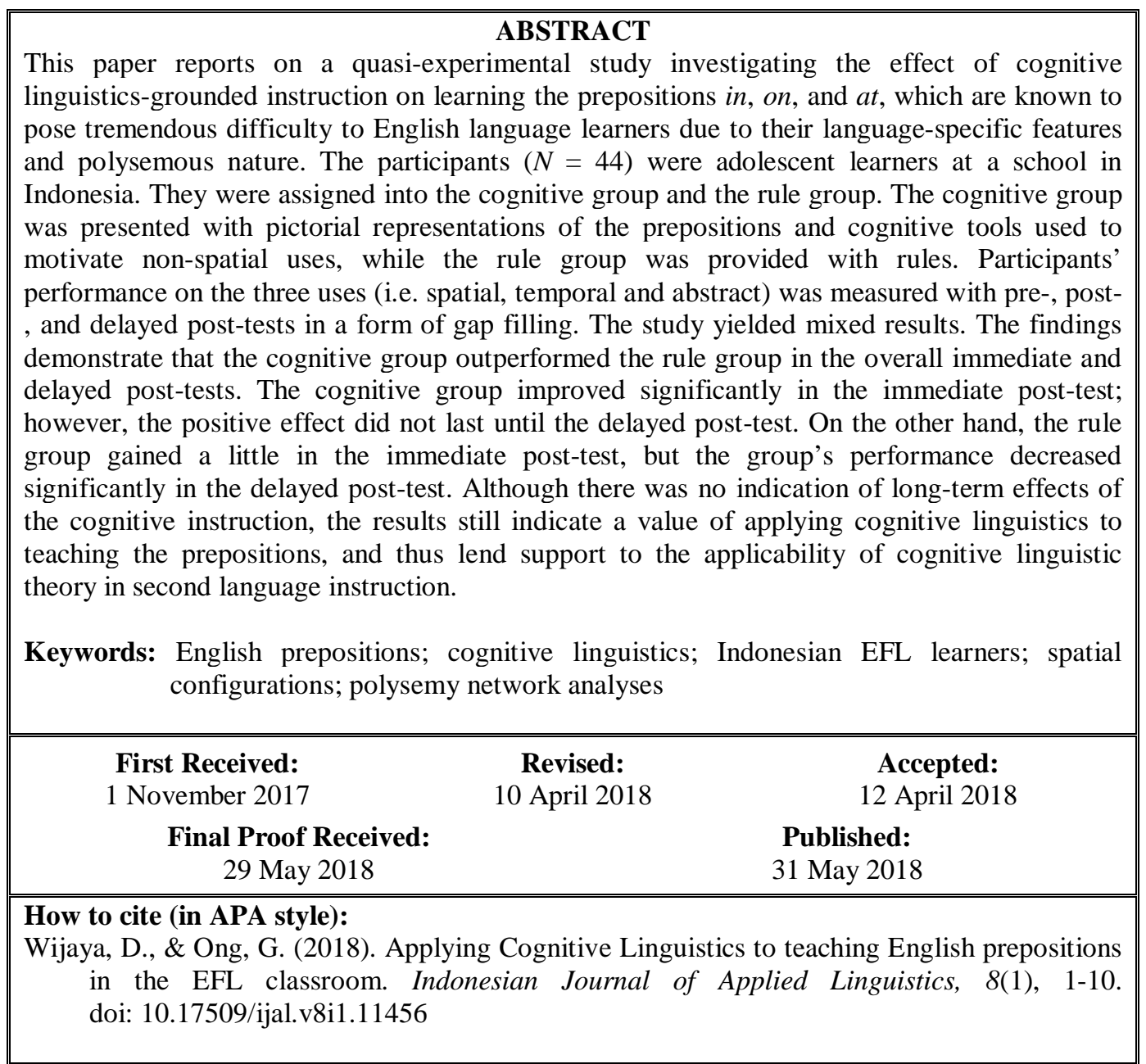

\section{INTRODUCTION}

Research has shown that not all approaches to second language (L2) instruction bring the same effects (DeKeyser \& Sokalksi, 2001; Ellis, 2005; VanPatten \& Cadierno, 1993), and language structures vary in terms of their learnability, which means some structures are acquired earlier than others (Goldschneider \& DeKeyser, 2001). Furthermore, later acquired structures typically encode language-specific concepts that make them susceptible to first language (L1) influence (Jarvis
\& Pavlenko, 2008; Murakami \& Alexopoulou, 2016). English prepositions in, on, and at, are such language features that pose difficulty to English language learners and therefore are acquired much later (Celce-Murcia \& Larsen-Freeman, 1999). This difficulty can be attributed to their language-specific characteristics and therefore they do not always have perfect equivalents in other languages (Jarvis \& Pavlenko, 2008).

Current research has shown that even advanced L2 speakers never attain native-like use of this linguistic

\footnotetext{
* Corresponding author:

Email: david.wijaya@atmajaya.ac.id
} 
feature, especially when the speakers' L1 largely differs from the L2 in the ways the language conceptualizes spatial relationships (Alonso, Cadierno, \& Jarvis, 2016). Alonso et al. (2016) set out to investigate the use of prepositions by advanced EFL learners from two language backgrounds, Danish and Spanish, by focusing on how these learners construed spatial configurations that English native speakers refer to with the prepositions in, on, and at. They also explored the extent to which the learners' L1 spatial construal patterns influenced their construal of these English spatial configurations. They found that the Danish learners' performance was very similar to the native English speakers'. In contrast, the Spanish learners produced a variety of prepositions for each item. They attributed these results to the influence of the learners' L1s. Danish has three prepositions that are approximately equivalent to the English prepositions in question (i.e. $\mathrm{P} \AA=$ on, $\mathrm{I}=i n$, and $\mathrm{VED}=a t$ ). Spanish native speakers, on the other hand, use the preposition EN that covers the three English prepositions. In other words, the task of learning to construe the English spatial configurations is much less challenging for Danish speakers as their construal and linguistic encoding of space is very similar to those of English native speakers. However, Spanish speakers do not categorize meanings of prepositions like English and Danish; rather, they mark locations in a more general way. Consequently, their choices of the English prepositions tend to be incongruent with the spatial construal patterns in English (Alonso et al., 2016).

It could be argued that Indonesian native speakers construe spatial configurations and linguistically encode them in much the same way with Spanish native speakers. According to Sneddon (2010), the preposition DI is used as a basic locative preposition in Indonesian and covers the English prepositions in (e.g. "lagi di kelas" = in the class), on (e.g. "laba-laba di dinding" = a spider on the wall), and at (e.g. "sedang di tempat pesta" = at the party). Given the similarity of Indonesian and Spanish in terms of spatial categorization, one could argue that Indonesian learners are also influenced by their L1 as they express spatial relationships in English that require them to use in, on, and at. This crosslinguistic influence will manifest itself in their inaccurate prepositional choices.

Moreover, the prepositions are not strictly used to describe a spatial relationship between two entities (e.g. Mom is in the kitchen) but also to describe time (e.g. I have a class on Monday) and situations that are usually abstract (e.g. I'm in love). These multiple uses have traditionally been regarded as arbitrary, unrelated and unsystematic (Chomsky, 1995). The distinct uses coded by the same preposition are presumably coincidence. However, a growing body of literature has indicated that prepositions, similar to other polysemous words, constitute radial networks, with the spatial senses located at the core, and temporal and abstract senses, which are more metaphorical, radiating out towards the periphery (Tyler \& Evans, 2001; Taylor, 2002). In other words, the peripheral senses of a given preposition are systematically and metaphorically related to its core sense. To be sure, L2 learners experience tremendous difficulty in using the more peripheral senses of prepositions (Krzeszowski, 1990 as cited in Jarvis \& Pavlenko, 2008; Ijaz, 1986), especially if the learners speak a verb-framed language (i.e. a language which encodes both manner and path in the verb) which does not employ phrasal verbs (Alejo, 2008, as cited in Littlemore, 2009).

These difficulties indicate that L2 learners need pedagogical treatments to assist them to make better prepositional choices. Conventional treatments suggest rote-memorization as the only learning strategy, reflecting the traditional theoretical accounts of language that treat prepositions as arbitrary, unrelated homonyms governed by rules. The problem with this strategy lies in the ways that daily usage of language cannot be simply accounted for by the proposed rules, especially in contexts where more than one preposition is possible (Matula, 2007). In line with Alonso et al. (2016) and Tyler (2012), there is a need to apply a usage-based approach to language and language pedagogy, and research should be conducted to investigate the effect of such approach on learners' acquisition of prepositions.

Cognitive Linguistics (henceforth CL) is a usagebased approach to investigating language. The proponents of CL contend that "learning language involves determining structure from usage” (Ellis \& Robinson, 2008, p. 3) and "knowledge of language emerges from language use” (Croft \& Cruse, 2004, p. 3 ). Unlike the generative perspective of language which understands language as an autonomous entity and separated from cognition, CL views language as meaningful and reflecting human general cognitive processes, such as perception and categorization. It thus posits that meaning is embodied (i.e. constructed from our experience with the social and physical world) (Croft \& Cruse, 2004; Tyler, 2012). This perspective on language has relevant implications to L2 instruction (Littlemore, 2009).

CL-informed L2 instruction provides learners with cognitive tools, as opposed to rules that they can use to learn the target structure. The tools emphasize connections between multiple meanings of a linguistic form and image schemas, and are presented to learners in accessible meta-language (Arnett \& Jernigan, 2014). The tools can be effective problem solving strategies to foster acquisition. It is argued that presenting the tools in instructional material will be pedagogically more beneficial for learners (Langacker, 2008; Taylor, 2008; Tyler \& Evans, 2003). Although several studies have proven the superiority of CL-based instruction over rule-based instruction (hereafter RI) (e.g. Tyler, Mueller, \& Ho, 2010; Tyler, 2012), more research is warranted to generalize the findings, especially in different contexts and populations, and thus generate further insights into applications of $\mathrm{CL}$ in $\mathrm{L} 2$ instruction. To date such research is scarce in the 
Indonesian context. Moreover, most CL studies used adult learners as their participants. Little is known about the effect of CL-based instruction on adolescent learners. One last limitation is concerned with experimenter bias. The instructors for the experimental groups in CL studies have always been the researchers who are well-versed in CL theory and believe in its usefulness in L2 instruction (Jacobsen, 2016). Up to now, it is not known whether CL learning materials can also be used by teachers who are not familiar with CL theory and have not yet formed opinions and beliefs regarding its usefulness for L2 instruction. Therefore, the current study attempted to investigate the relative effects of CL-informed instruction and RI by addressing the aforementioned limitations. It focused on the usefulness of CL in teaching the prepositions in, on, and at to adolescent Indonesian EFL learners.

\section{Cognitive analysis of the prepositions in, on and at}

Before turning to the current study, it is necessary to discuss how English prepositions are viewed through the lens of CL to set the theoretical basis for devising appropriate pedagogical materials. According to CL, a preposition is polysemous-one word having different, yet systematically related and motivated senses. The spatial preposition carries a core sense that is derived from our interaction with physical entities in the world and based on our sensory perception of our surroundings (Langacker, 2008). The other senses (i.e. temporal and abstract senses) are derived from the core sense in a systematic way. Research into this systematicity has resulted in polysemy network analyses that demonstrate how the core sense metaphorically motivates the extended senses. That is, the extension of the spatial sense to the temporal one is motivated by the metaphor TIME AS PHYSICAL SPACE or PHYSICAL OBJECT (Evans, 2003) that can be measured, while the extension to non-temporal abstract senses is motivated by the metaphor ABSTRACT OBJECTS AS CONCRETE OBJECTS (Evans, 2003; Lakoff \& Johnson, 1980) that can be counted, given and owned.

There are two additional cognitive principles needed to motivate the extension to the topology of abstract space and show the link between spatial and abstract: functional aspects and topological relations. As one could easily observe, a spatial configuration consists of a figure (F), which is typically smaller and more eye-catching, and a ground $(\mathrm{G})$, which is usually bigger and less eye-catching, as well as a functional element (Radden \& Dirven, 2007). In general, the functional element of a preposition comprises meaningful consequences that stem from the relationship between F and G (Tyler \& Evans, 2003). In fact, it is the functional aspect, not the visual configuration that helps us link the extended senses to the core sense (Matula, 2007). The notion of topological relations holds that we do not need to be concerned with the shape and size of the $F$ and $G$ in order to decide the correct preposition as we can construct a pictorial representation that consists of a shared spatial-physical representation. The following section presents polysemy network analyses of the target prepositions.

In English, to determine the spatial area where an object is located, we need to specify the dimension of the ground. As one could easily notice, the dimensions expressed by the prepositions at, on, and in are zero, one, two and three respectively. The zero dimensional preposition at is used when the $\mathrm{G}$ is seen as a reference point to locate an F. The preposition on is used when the $\mathrm{G}$ is seen as either a line (one dimension), or a surface (two dimensions). The preposition in is used when the $G$ is seen as a containment, which is three-dimensional. It must be acknowledged here that recent non-cognitive instruction on the prepositions also utilizes visual aids, such as pictures, to assist learners to see how they are different from each other in describing spatial relations (cf. Murphy, 2012). Another technique is to encourage learners to decide the dimension of the $\mathrm{G}$ (Celce-Murcia \& Larsen-Freeman, 1999). While these techniques may be somewhat useful to understand the spatial uses, they are not very insightful when it comes to explaining the difference between:

(1) I'm at the hospital and

(2) I'm in the hospital.

Moreover, they do not make any mention of the functional elements and their consequences, nor do they provide learners with any visual aids to comprehend the prepositions used in non-spatial senses. To account for the uses in the extended senses, we must identify the functional aspect of each preposition and consider the consequences that follow.

As mentioned above, a functional element, along with its consequences, arises from the spatial relation between an F and a $\mathrm{G}$ (see figure 1). In the case of at, an $F$ is located either in the same location with or very near to a G (Tyler \& Evans, 2003). Thus, its functional aspect involves proximity and orientation (or pointing). Also, at is zero-dimensional because the particular spatial dimension of a $G$ is unspecified and irrelevant. As for on, an $F$ is in direct contact with the surface of the G. The contact is set up by gravity, which makes the $F$ rest upon the $G$. The $G$ counteracts the force of gravity by functionally supporting the F. Finally, for in, an $F$ is seen as being contained or bounded by the $G$. The functional aspect of containment has several consequences, such as protection and control of activity inside the G's environment.

This explication helps us see how (1) differs from (2). In (1) the $F$ is free to move in the hospital area, while in (2), the F's movement is strictly controlled by the hospital's regulations due to some health issues this someone is experiencing. In CL tradition, it is common to assume that our understanding of time is conceptualized in terms of space (Evans, 2003; Tyler \& Evans, 2003; Wierzbicka, 1993). Therefore, English prepositions can also be used to describe relations in the topology of time and account for the temporal uses of 
the prepositions by means of the metaphor TIME IS SPACE, their functional aspects and topological relations (see figure 2). This contradicts the traditional way of describing temporal prepositions. Textbook rules often state that for clock time use at, days and dates on, and longer periods in (cf. Murphy, 2012). Such rules, however, do not attempt to figure out the link between temporal and spatial prepositions.

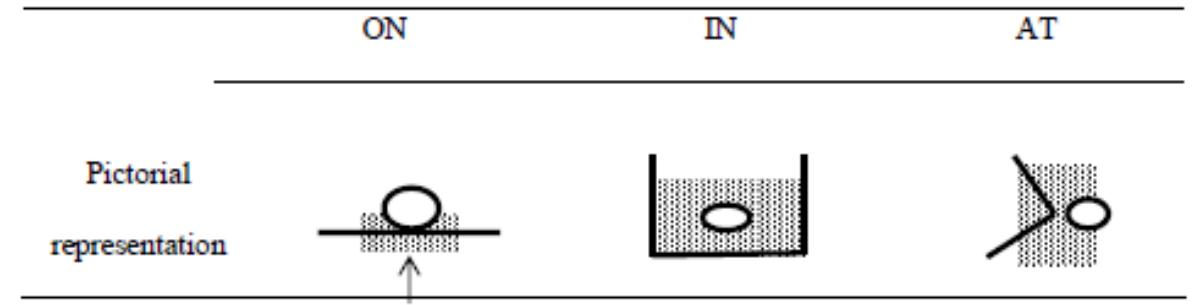

Figure 1: image representations of the prepositions on, in, and at (Matula, 2007, p.130)
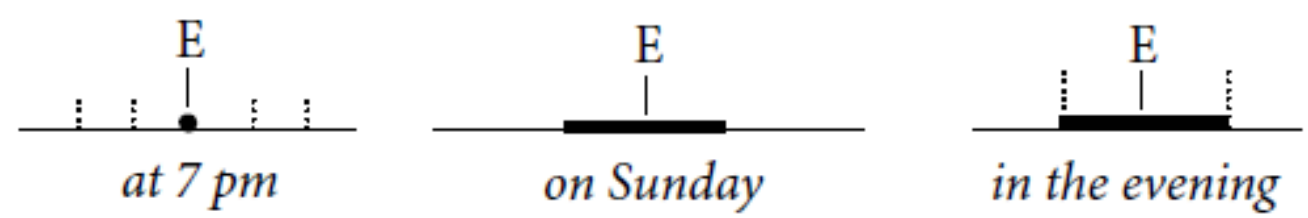

Figure 2. Temporal dimensions of the prepositions at, on and in (Radden \& Dirven, 2007, p. 321)

As spatial at refers to a point in space, temporal at refers to a point in time. To better understand this, it is helpful to observe the clock: the hands show the act of directing or orientation towards a particular numerical time unit. In the case of on, the preposition is used to describe contact of our activities with days (e.g. Sunday) and parts of days (such as, Sunday morning) since "days are particularly salient units on which our routine activities are organized" (Radden \& Dirven, 2007, p. 321). The way we use organizers to arrange our schedules in detail confirms this proposition. As in the temporal in, a $G$ is described as a time frame with a beginning and an end as temporal boundaries. The use of at for a holiday is appropriate when the $G$ (e.g. Christmas) is construed as not only one particular day (i.e. December $25^{\text {th }}$ ) but also an extended period of time (some days before and after December $25^{\text {th }}$ but it is still considered Christmas), while on is used when an event (the F) takes place on December $24^{\text {th }}$. This analysis can be used to explain the distinction between in time and on time. The use of in time refers to an extended time frame, while on time is used if the time frame is seen as not having internal parts (Matula, 2007).

We can still rely on the same conceptual tools to account for the uses in the topology of abstract space where prepositions are used to describe conditions and situations (Radden \& Dirven, 2007).

The above explications confirm the fact that prepositions are indeed highly polysemous: they consist of distinct yet metaphorically motivated and systematically related senses. As argued above, a presentation consisting polysemy network analyses may have a better value since learners can use the analyses as their cognitive tools. Indeed, as also argued elsewhere, "learning an extended meaning is easier than learning a meaning that is unrelated to a familiar one” (Frisson et al., 1996, p. 616).
Several studies have been done to provide evidence that a CL approach is facilitative in teaching English prepositions. Tyler (2012) reported two studies in which the English prepositions to, for and at were taught to a group of advanced Italian ESL learners (Tyler, Mueller, \& Ho, 2010) and a group of less homogenous, college-aged Vietnamese EFL learners. The results of the two studies indicate that most of the participants gained significantly on the posttest after receiving a CL-based treatment. Of relevance to the present study is Matula's (2007) study as she addressed the same prepositions with ours. The experiment reported in her unpublished doctoral dissertation investigated the effects of a CL-incorporated instruction and a traditional type of instruction on twenty intermediate-level ESL learners' acquisition of the spatial and temporal senses of the prepositions in, on, and at. Although neither group significantly outperformed the other on the post- and delayed posttest, the cognitive group showed "more consistent increase in correct use across the senses and tasks" (Matula, 2007, p. iv). Moreover, data from the oral stimulated recalls revealed that the cognitive group's explanatory scores increased significantly after the treatment, while the traditional group's score did not. The qualitative aspect of the study also indicated that the non-cognitive participants felt unsatisfied with the provided rules. They wanted a more comprehensive and complete explanation than a list of rules to be memorized to account for everyday usage of the target prepositions.

Several limitations of her study exist, which warrant further research. Her study was conducted in an ESL context where the participants got exposed to the target language outside the classroom. In an EFL context, input for learners is extremely limited. Doing a similar study in this context may yield a different result. Moreover, her participants came from various L1 
backgrounds. Having a group of learners who speak the same L1 as subjects may reveal not only the effect but also the effect size to the speakers of a particular language. Indonesian, as argued above, is very different from English in terms of spatial configuration. Indonesian EFL learners need to learn new spatial meanings and distinctions not carried by their general preposition DI and move from one category in Indonesian to multiple categories in English. However, research investigating the effect of CL-based instruction on their acquisition of these prepositions is yet to be available. Finally, Matula (2007) only addressed two senses, the spatial and temporal senses. Given that the abstract sense also poses great difficulty to learners, it is worth investigating whether the instruction can also assist learners to make correct prepositional choices in this sense.

To sum up, the review of previous research above necessitates another investigation into applications of CL-based instruction to teaching the target prepositions. In general, we seek to experimentally investigate whether this approach may be more effective than the rule-based approach in an Indonesian EFL school context by addressing the following research questions.

1. What are the relative effects of CL-based instruction and rule-based instruction in assisting adolescent Indonesian EFL learners to use the correct prepositions in the three senses (i.e. spatial, temporal and abstract) as measured by a gap filling component?

2. If there are any advantages of one sort of instruction over the other, will these advantages be proved durable for two weeks?

\section{METHOD \\ Participants}

The participants involved in this study were tenth grade students, aged 14 to 15 , at a school in Jakarta, Indonesia. They sat in four pre-determined intact classes. Due to the regulations of the school, we were only allowed to randomize the classes and categorize them into two groups: the CL group and the RI group. Before the experiment, the students were informed of the research and its purpose. They all agreed to participate in the experiment. They spoke Indonesian as their first language and had been learning English as a mandatory subject since they were in grade seven. Although the initial pool of the participants was eighty five, those who scored $70 \%$ or better on the pre-test were eliminated from analysis as they were assumed to have had sufficient knowledge of the target prepositions along with the senses. In the end, each group consisted of 22 learners.

\section{The treatment}

The pedagogical treatment lasted for 70 minutes. Our research assistant who had been doing her internship at the school for two months was chosen to be the instructor for both groups. She had had no prior knowledge of CL theory. She was informed to follow the instructions in the handouts for both groups and given some time to familiarize herself with the materials. The participants were familiar with her and thus not hesitant to ask questions during the lesson. The instructor used both Indonesian and English during the presentation to ensure participants' comprehensibility.

a. CL instructional materials: Our CL instructional packet differs from Matula's (2007). In our packet, we did not begin with the cognitive tenets (i.e. polysemy, metaphors, and topological relations) as we believed these tenets should be introduced when the teacher links the spatial sense with the other two senses. Furthermore, we did not include any total physical response activities due to the different class size. Instead, we provided participants with handouts and PowerPoint presentations. Our treatment was also much shorter. PowerPoint slides were utilized to make the presentation more meaningful and interactive. To begin with, participants were informed that they were going to learn about the target prepositions. They were asked what each preposition meant. They quickly gave the Indonesian definitions for in and on, but were unable to tell the meaning of at. They were then explained how the three prepositions differed from Indonesian prepositions and that English prepositions have multiple but systematically related meanings. This was meant to raise their awareness of how English and Indonesian differ in the way each language construes spatial configurations. Then, they were introduced to the functional aspect and core meaning of each spatial preposition through pictures, diagrams (i.e. the image representations of the prepositions) and examples shown on PowerPoint slides. Participants received three sets of instruction in a row. In each set, example sentences along with their accompanying pictures, functional aspects and core meanings were provided to enhance participants' understanding of the form-meaning relationships. Two tasks were provided for each sense too (see appendix). After they finished doing the first task, they were shown the correct diagrams with the core meanings and functional aspects on slides. Participants compared their answers with the answers shown on the slides. They were told to refer back to the cognitive explanation in their handout if they had different answers but did not understand why their answers were not appropriate. In the second task, participants were given a more traditional type of exercise: a fill-in-the-gaps activity. The same procedure of feedback for the first task was repeated. No explanation was provided for the answers. The instructor concluded lesson by reminding the participants how the English prepositions differ from the Indonesian preposition, how the three senses of the 
prepositions are systematically related, and how to decide which preposition to use.

b. Rule-based instructional materials:

At the outset, participants were shown three pictures with three sentences describing the pictures. They were then asked to match the sentences with the pictures. The answers were shown once they were done with this task. Afterwards, participants received an instructional packet that consisted of a handout note and exercises. Unlike Matula's (2007) traditional treatment materials, our materials were adapted from Murphy's (2012) grammar textbook. In line with the emphasis of traditional presentations of grammatical features, the note contained pictures for the spatial sense; simple rules for the temporal sense (e.g. at for the time of day); and examples for the abstract uses (e.g. sit in the shade). No attempts were made to make connections between the spatial sense and the other senses. The instructor also used Powerpoint slides to present example sentences, the accompanying pictures, and the rules. For each unit, after the teacherfronted explanation, the participants did a gap filling task and were shown the answers to the exercise. Similar to the CL group, the instructor had the participants refer back to the note for the explanation. To conclude, the instructor reviewed the three uses of the prepositions.

\section{Pretests and posttests}

Three tests were created, with each consisting of thirty discrete fill-in-the-gap items missing only prepositions. This fill-in task was chosen due to the limited allocated time given by the school. Ten sentences were on the spatial sense, nine on the temporal sense and nine on the abstract sense. The other three items were distractors and therefore were not scored. They were piloted with another group of learners who were at the same age to ensure test clarity and identify ambiguous usage (i.e. two choices of prepositions were arguably possible). Technical errors and unfamiliar word choice were revised, and the ambiguous items were replaced with items that could only have single definite answers.

\section{RESULTS}

The overall pretest scores show that the CL group scored slightly higher than the RI group did (see Table 1). However, a Mann-Whitney Test indicates that the difference was not significant, $U=168.50, z=-1.745, p$ $=0.081$. In other words, the two groups were comparable in their performance prior to receiving treatment. As can be seen in table 1, the means of both groups of the pretest were: $\mathrm{CL}=15.41$ and $\mathrm{RI}=14.14$. These means increased to $\mathrm{CL}=18.23$ and $\mathrm{RI}=15.45$ on the immediate posttest. On the delayed posttest, the CL group's mean slightly increased to 15.73 , however the RI group's mean decreased to 8.91.

Table 1. Descriptive statistics

\begin{tabular}{lcccccc}
\hline \multirow{2}{*}{ Group } & \multicolumn{2}{c}{ Pretest } & \multicolumn{2}{c}{ Immediate posttest } & \multicolumn{2}{c}{ Delayed posttest } \\
\cline { 2 - 6 } & $\mathrm{M}$ & SD & $\mathrm{M}$ & SD & \multicolumn{1}{c}{ M } & SD \\
\hline CL & 15.41 & 2.9 & 18.23 & 2.70 & 15.73 & 2.07 \\
RI & 14.14 & 2.5 & 15.45 & 3.20 & 8.90 & 2.40 \\
\hline
\end{tabular}

To answer our first research question, a MannWhitney Test was performed on the participants' scores in the immediate posttest. The result indicated that the two groups' overall performance differed significantly in their uses of the prepositions in the three senses, with the CL group outperforming the RI group, $Z=-3.304, p$ $=.002$. The average gain the CL group experienced from pretest to immediate posttest was also significant, $Z=-3.851, p=.000$. The RI group's improvement, on the other hand, was not significant, $Z=-1.802, p=.072$. A closer look at the two groups' performance in each sense immediately after treatment revealed that the RI group had a bigger gain in the spatial sense. However, the CL group showed bigger gains in the other two senses. Wilcoxon signed-rank tests conducted on the pretest and posttest scores of each group in each sense demonstrated that the CL group improved significantly only in the temporal sense, $Z=-3.206, p=.001$, and the RI group made no significant improvement in all the senses. The gains for individual senses in the immediate posttest are shown in Table 2.

Table 2. Gains for individual senses in the immediate posttest

\begin{tabular}{lcrrrrrrrr}
\hline & $\begin{array}{c}\text { spatial } \\
\text { Pre }\end{array}$ & $\begin{array}{c}\text { spatial } \\
\text { Imm. }\end{array}$ & $\begin{array}{c}\text { spatial } \\
\text { Gain }\end{array}$ & $\begin{array}{c}\text { temporal } \\
\text { Pre }\end{array}$ & $\begin{array}{c}\text { temporal } \\
\text { Imm. }\end{array}$ & $\begin{array}{c}\text { temporal } \\
\text { Gain }\end{array}$ & $\begin{array}{c}\text { abstract } \\
\text { Pre }\end{array}$ & $\begin{array}{c}\text { abstract } \\
\text { Imm. }\end{array}$ & $\begin{array}{c}\text { abstract } \\
\text { Gain }\end{array}$ \\
\hline CL & $63.6 \%$ & $70 \%$ & $\mathbf{6 . 4 \%}$ & $61.6 \%$ & $75.7 \%$ & $\mathbf{1 4 . 1 \%}$ & $46.4 \%$ & $56.5 \%$ & $\mathbf{1 0 . 1 \%}$ \\
RI & $47.3 \%$ & $55.9 \%$ & $\mathbf{8 . 6 \%}$ & $71.2 \%$ & $70.6 \%$ & $\mathbf{- 0 . 6 \%}$ & $37.3 \%$ & $46 \%$ & $\mathbf{8 . 7 \%}$ \\
\hline
\end{tabular}

To answer our second research question, a MannWhitney Test was conducted on the participants' delayed posttest scores. The result revealed that the CL group was far superior to the RI group, $\mathrm{Z}=-5.509$, $\mathrm{p}=$ .000 . The CL group's score decreased from immediate posttest to delayed posttest however the score in the delayed posttest was slightly higher than the pretest. A Wilcoxon signed-rank test indicated that the difference was not significant, $Z=-.071, p=.943$. On the other hand, the RI group's score decreased dramatically from posttest to delayed posttest, yielding a delayed posttest score which was lower than the pretest score. In terms 
of both groups' performance in individual senses (see table 3), the CL group improved little only in the spatial sense, while the RI group showed no gains at all. The answer to the second research question is that in the case of the CL group, the positive effect was not durable to the delayed posttest while in the case of the RI group, their performance in the delayed posttest unexpectedly worsened.

Table 3. Gains for individual senses in the delayed posttest

\begin{tabular}{cccccccccc}
\hline & spatial & spatial & spatial & temporal & temporal & temporal & abstract & abstract & abstract \\
& Pre & Del. & Gain & Pre & Del. & Gain & Pre & Del. & Gain \\
\hline CL & $63.6 \%$ & $67.3 \%$ & $\mathbf{4 . 0} \%$ & $61.6 \%$ & $61.6 \%$ & $\mathbf{0 . 0} \%$ & $46.4 \%$ & $39.8 \%$ & $\mathbf{- 6 . 6 \%}$ \\
RI & $47.3 \%$ & $32.7 \%$ & $\mathbf{- 1 4 . 6 \%}$ & $71.2 \%$ & $33.3 \%$ & $\mathbf{- 3 7 . 9 \%}$ & $37.3 \%$ & $33.8 \%$ & $\mathbf{- 3 . 5 \%}$ \\
\hline
\end{tabular}

\section{DISCUSSION}

The outcomes of our study reveal some interesting findings. Our study found that CL-based instruction was superior to RI when the subjects were tested immediately after treatment. The CL participants also showed gains in all the three senses, although they improved significantly in the temporal sense. The participants in the RI group showed insignificant gains only in the temporal sense. This result is attributable to the nature of the instruction each group received. The CL group was trained, by means of core meanings and functional aspects, to construe spatial configurations in the way English speakers do. The diagrams that we asked them to draw may also have induced noticing the configurations and subsequently affected their perceptual judgments when performing in the target language. This practice on perceptual processing has been argued to bring about perceptual learning (Özgen \& Davies, 2002; Goldstone, 2003). Consequently, they were able to make more informed decisions as to which spatial prepositions they had to use. The training equipped the participants with analytical tools to connect the core meanings with the extended meanings. Having these tools at their disposal resulted in gains in all the senses albeit the gains were not significant. Arguably, the tools were helpful to foster acquisition. This lends support to Frisson et al.'s (1996) argument that learners will find it easier to learn an extended meaning rather than an unrelated meaning.

In the case of the RI group, although they were presented with pictures to help them understand how the prepositions differ from each other, they were not given image representations that could enhance learning. They may also have become insensitive towards this kind of visual presentation as they had experienced learning the target prepositions in the same way in the past, and consequently they might have paid very little attention to the pictures accompanying the example sentences during the teacher-fronted explanation. Moreover, in learning the non-spatial senses, the learners were only provided with rules. Rules are consciously processed (Hampton 2005), and this processing draws on working memory capacity (Baddeley, 2000). However, knowing rules does not entail activation of the knowledge during language production (Godfroid, 2016), thanks to our limited working memory capacity. Thus, the participants in the RI group were arguably not successful to recall all the uses that had been taught.
Regarding the long-term effectiveness of both approaches, the result indicated that the positive effect experienced by the CL group did not hold until two weeks after treatment and the RI group's mean score on the delayed posttest decreased drastically. One reason for this could be boredom (Mackey \& Gass, 2005). This extra-experimental factor could have affected the participants' responses while they were doing the task in the delayed posttest since the task was repetitive in nature. Motivation might have also played a role. Adolescent learners who are studying a foreign language in a school setting typically have lower motivation (Li, 2015). The lack of motivation in doing the test may have caused inattentiveness among some learners. However, the fact that the CL group still showed a slight gain on the test, while the RI group decreased significantly, indicated that the CL group may still have been able to utilize the cognitive tools. For the RI group, doing a delayed posttest must have decreased their motivation to provide proper responses to the task at hand, especially when they had to rely on their limited working memory capacity. Our one last assumption regarding these unsatisfying delayed posttest results is that the length of treatment was considerably short given the complex semantic concepts the learners had to get used to. Perceptual learning takes place if a stimulus is attended to habitually and repeatedly (Goldstone, 2003). Due to the very limited treatment time, the numbers of visual stimuli (i.e. pictures and diagrams) presented in both groups were arguably far from sufficient to yield long-term learning.

To sum up, the claim that CL-oriented researchers (e.g. Tyler, 2012) made regarding the efficacy CLinformed L2 instruction should be accepted with reservations based on the outcomes of the present study. For Indonesian EFL learners, learning these English prepositions requires them to restructure their conceptual category of space and understand how the spatial categories of the target language that serve as core meanings of the prepositions are systematically extended to non-spatial uses. To use a preposition in a more target-like way requires us to rethink of how spatial relationships are coded in the L2. This "thinking for speaking” (Slobin, 1996, p. 76) is a key process that L2 learners have to go through as they prepare their thought for producing the language. Simply getting learners to memorize the uses and rules is wanting. Although the effect of CL-based instruction was not durable for two weeks, based on our findings, we would 
encourage English teachers to apply this technique when giving explicit instruction of the prepositions and remind their students about the core meanings and functional aspects whenever they are struggling to make prepositional choices.

It is also interesting to discuss the role of instructor here. As mentioned earlier, the instructor for the CL group was someone who had no prior knowledge of CL research and was therefore neutral in her position regarding the usefulness of CL as a viable approach to ELT. Jacobsen (2016) argues that CL materials can only be utilized by those who have undergone prior training in CL and formed positive opinions and beliefs regarding the efficacy of CL-oriented L2 instruction. Our findings demonstrate that this is not always the case. It is possible to develop CL materials, such as ours, that could be used by teachers who have little or no prior understanding of CL theory.

At this point, the limitations of the current study should be pointed out. The task to measure learners' performance was only gap-filling, which, as argued earlier, might have caused boredom and inattentiveness. Thus, future research should use various tasks (e.g. picture comprehension and picture description, as in Matula's study). These tasks will also allow us to properly investigate and analyze learners' use of the prepositions in the three senses. Furthermore, providing longer instructional treatment in future research might yield different results.

The tasks for the CL group in our treatment could also be improved for further experiments. Our first task might have been time-consuming and unsuitable for those who were not very used to drawing. We would propose that in the next experiment the input-based task only requires learners to choose the diagram that represents the core meaning. This will also allow the teacher to provide more visual stimuli to the students. For an output-based task, learners could be asked to describe pictures so that the learning will be more meaningful. It would be interesting to see whether this improved CL-incorporated treatment will yield different results.

\section{CONCLUSION}

The study set out to investigate the effect of integrating CL insights into the teaching of the prepositions in, on, and at. The findings show that in the overall scores, the CL group performed significantly better than the RI group in both the immediate and delayed post-tests, although the positive effects of the CL learning materials were not durable to the delayed post-test. These results demonstrate a pedagogical value of CLinformed L2 instruction (Matula, 2007).

\section{ACKNOWLEDGEMENT}

This article is based on part of the second author's unpublished research report which was submitted to her university in 2016. The authors wish to thank Dr.
Suzanne Matula of Georgetown University for Language Education and Development for graciously sharing her dissertation with the authors, Dr. Agustian Sutrisno and one anonymous reviewer for their insightful comments on earlier versions of this paper, the students in grade X batch 2015/2016 at Kanaan Senior High School for being our participants and Ms. Cindy Carla for being the instructor for both groups. Any remaining errors are ours.

\section{REFERENCES}

Alonso, A. R., Cadierno, T., \& Jarvis, S. (2016) Crosslinguistic influence in the acquisition of spatial prepositions in English as a foreign language. In A. R. Alonso (Ed.) Crosslinguistic Influence in Second Language Acquisition (pp. 93-120). Clevedon: Multilingual Matters.

Arnett, C., \& Jernigan, H. (2014). A cognitive grammar account of case for L2 students of German. German as a Foreign Language, 1, 6893.

Baddeley, A. (2010). The episodic buffer: a new component of working memory? Trends in Cognitive Sciences, 4(11), 417-423.

Celce-Murcia, M. and Larsen-Freeman, D. (1999). The grammar book: An ESL/EFL teacher's course. New York, NY: Heinle \& Heinle.

Croft, W. and Cruse, D. A. (2004). Cognitive linguistics. Cambridge: Cambridge University Press.

Chomsky, N. (1995). The minimalist program. Cambridge, MA: MIT Press.

DeKeyser, R., \& Sokalski, K. J. (2001). The differential role of comprehension and production practice. Language Learning, 51, 81-112.

Ellis, N. C. (2005). At the interface: Dynamic interactions of explicit and implicit language knowledge. Studies in Second Language Acquisition, 27, 305-352.

Evans, V. (2003). The structure of time: Language meaning and temporal cognition. Amsterdam/Philadelphia: John Benjamins Publishing Company.

Frisson, S., Sandra, D., Brisard, F., \& Cuyckens, H. (1996). From one meaning to the next: The effects of polysemous relationships in lexical learning. In M. Pütz \& R. Dirven (Eds.), The construal of space in language and thought (pp. 613-647). Berlin: Mouton de Gruyter.

Godfroid, A. (2016). The effects of implicit instruction on implicit and explicit knowledge development. Studies in Second Language Acquisition, 38(2), 177-215.

Goldschneider, J. M., \& DeKeyser, R. (2001). Explaining the "natural order of L2 morpheme acquisition” in English: A meta-analysis of multiple determinants. Language Learning, 51, 150. 
Goldstone, R. L. (2003). Learning to perceive while perceiving to learn. In R. Kimchi, M. Behrmann, \& C. Olson (Eds.), Perceptual organization in vision: Behavioral and neural perspectives (pp. 233-278). Mahwah, NJ: Erlbaum.

Hampton, J. A. 2005. Rules and similarity - a false dichotomy. Behavioral and Brain Sciences 28(1), 26.

Ijaz, I. H. (1986). 'Linguistic and cognitive determinants of lexical acquisition in a second language', Language Learning 36, 401-51.

Jarvis, S., \& Pavlenko, A. (2008). Crosslinguistic influence in language and cognition. New York, NY: Routledge.

Jacobsen, N. D. (2016). The best of both worlds: Combining cognitive linguistics and pedagogic tasks to teach English conditionals. Applied Linguistics, advance access, 1-27. doi: 10.1093/applin/amw030

Lakoff, G., \& Johnson, M. (1980). Metaphors we live by. Chicago, IL: University of Chicago Press.

Langacker, R. W. (2008). Cognitive grammar and language instruction. In P. Robinson \& N. Ellis (eds.) Handbook of cognitive linguistics and second language acquisition (pp. 66-88). New York: Routledge.

Li, S. (2015). The associations between language aptitude and second language grammar acquisition: A meta-analytic review of five decades of research. Applied Linguistics, 36, 385408.

Littlemore, J. (2009). Applying cognitive linguistics to second language learning and teaching. Basingstoke/New York: Palgrave Macmillan

Mackey, A., \& Gass, S. (2005). Second language research: Methodology and design. Mahwah, NJ: Lawrence Erlbaum Associates.

Matula, S. (2007). Incorporating a cognitive linguistic presentation of the prepositions on, in, and at in ESL instruction: A quasi-experimental study (Unpublished PhD dissertation). Georgetown University, Washington D.C.

Murakami, A., \& Alexopoulou, T. (2016). L1 influence on the acquisition order of English grammatical morphemes. Studies in Second Language Acquisition, 38(3), 365-401. doi: 10.1017/S0272263115000352.

Murphy, R. (2012). English grammar in use (4 $4^{\text {th }} \mathrm{ed}$.).
Cambridge: Cambridge University Press.

Özgen, E. \& Davies, I. R. L. (2002). Acquisition of categorical color perception: A perceptual learning approach to the linguistic relativity hypothesis. Journal of Experimental Psychology: General, 131, 477-493.

Radden, G., \& Dirven, R. (2007). Cognitive English grammar. Amsterdam: John Benjamins Publishing Company.

Robinson, P., \& N. Ellis (eds.). (2008). Handbook of cognitive linguistics and second language acquisition. New York, NY: Routledge.

Slobin, D. (1996). From "thought and language" to "thinking for speaking”. In S. Gumperz \& S. Levinson (eds.) Rethinking linguistic relativity (pp. 70-96). New York: Cambridge University Press.

Sneddon, J. N. (2010). Indonesian: A comprehensive grammar. London: Routledge.

Taylor, J. R. (2002). Cognitive grammar. Oxford, UK: Oxford University Press.

Taylor, J. R. (2008). Some pedagogical implications of cognitive linguistics. In S. De Knop \& T. D. Rycker (eds.) Cognitive approaches to pedagogical grammar: A volume in honour of Rene Dirven (pp. 37-65). Berlin: Mouton de Gruyter.

Tyler, A. (2012). Cognitive linguistics and second language learning: Theoretical basics and experimental evidence. New York, NY: Routledge.

Tyler, A., \& Evans, V. (2001). Reconsidering prepositional polysemy networks: The case of over. Language, 77, 724-765.

Tyler, A., \& Evans, V. (2003). The semantics of English prepositions: Spatial scenes, embodied meaning and cognition. Cambridge, UK: Cambridge University Press.

Tyler, A., Mueller, C., \& Ho, V. (2010). Applying cognitive linguistics to learning the semantics of English to, for, and at: An experimental investigation. Vigo International Journal of Applied Linguistics, 8, 181-206.

Van Patten, B., \& Cadierno, T. (1993). Explicit instruction and input processing. Studies in Second Language Acquisition, 15, 225-43.

Wierzbicka, A. (1993). Why do we say in April, on Thursday and at 10 o'clock? In search of an explanation. Studies in Language, 17, 437-454. 


\section{Exercise 1}

\section{Appendix 1: Input-based practice for the cognitive group}

There are ten sentences below. For each sentence, draw the preposition diagram that represents the sentence. Then, label the figure and the ground in the diagram. Write the meaning represented by the sentence. Finally, make a sentence similar to each sentence. The first one has been done for you.

\begin{tabular}{|c|l|l|l|l|}
\hline No. & \multicolumn{1}{|c|}{ Sentence } & Diagram & Meaning & New Sentence \\
\hline 1. & Ms. Anna is at the door. & & & \\
\hline
\end{tabular}

\section{Appendix 2: Samples of CL treatment slides}

The duck is at the door.

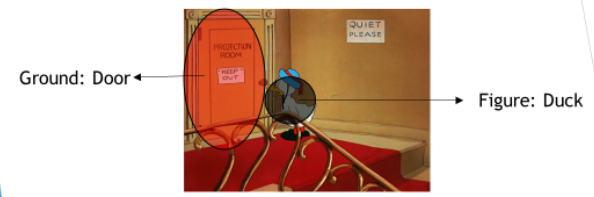

Point/pointing:

The duck and the door are very close to each other

$\rightarrow$ location of the duck = location of the door

I put your books on the nightstand.

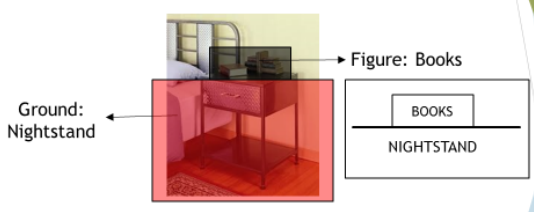

Contact/support:

The books are supported by the nightstand (they will fall withou the nightstand)

The books are touching the nightstand \& covers some of the nightstand

Someone put the kitten in a small box.

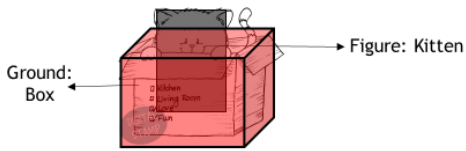

Containment:

- The kitten is inside the box.

- The kitten is limited by the boundaries of the box (e.g.: it cannot move easily inside the box)

At 12 years old, the tallest guy on Earth was already $2 \mathrm{~m}$ tall.

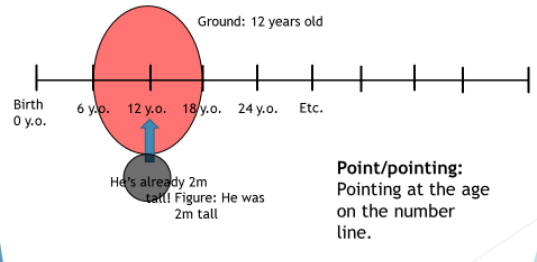

The train departs at 10:10.
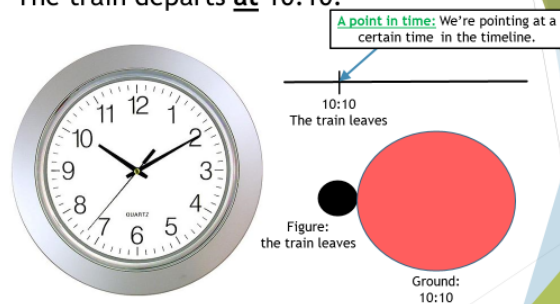

I was born on Friday, 18 May 2000.

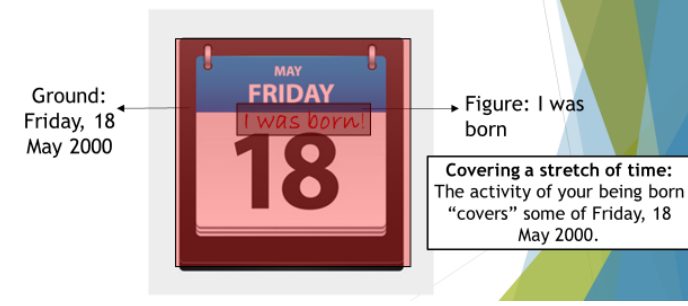

Mid-term exams are in September.

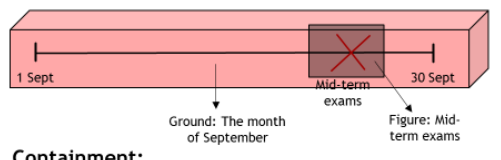

Containment:

- Boundaries: 1 and 30 Sept

- Mid-term exams are in September as long as they're between the boundaries

This also works for weeks, years, decades, etc.

I've never met her, but I've spoken to her on the phone.

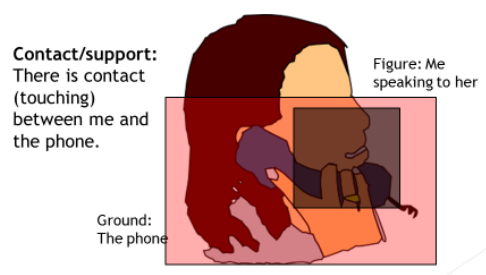

